\title{
Persistent low fertility among the East Asia descendants in the United States: perspectives and implications
}

\author{
Yong Cai ${ }^{1}$ (1) S. Philip Morgan ${ }^{1}$
}

Received: 9 December 2018 / Accepted: 29 January 2019 / Published online: 8 February 2019

(c) China Population and Development Research 2019

\begin{abstract}
We focus on a small but growing segment of the U.S. population, those who identify as Chinese, Japanese and Korean (CJK), and compare CJK fertility to other race/ethnic groups in the United States. CJK women in the U.S. exhibit a distinct, pervasive, and persistent pattern of late and low fertility with nearly all births occurring within marriage; this pattern displays a strong parallel to their counterparts in their countries of origin. To accompany this description, we offer a perspective on fertility difference that has broad applicability and that does not consistently predict that differences will disappear/remain. This discussion unites the literature on assimilation, segmented assimilation and pluralistic outcomes and processes. We also discuss the possible implications of these findings for country level policies to increase fertility. Most generally, these discussions are a corrective to demographer's penchant for predicting secular change and convergence.
\end{abstract}

Keywords Low fertility - Chinese/Japanese/Korean - Theory of conjunctural action · Segmented assimilation - U.S. fertility differences

\section{Introduction}

In his presidential address at the 2003 Population Association of America (PAA) Annual Meeting, Morgan (2003) asks whether "low fertility is a twenty-first century demographic crisis" based on the observation that "nearly half of the world's population in 2000 lived in countries with fertility rates at or below replacement level," and nearly all countries were projected to "reach low fertility levels in the next two decades." His answer was negative, because he saw both persistent rationales for having children and possibilities of institutional adjustments and public policy options that would make near replacement level fertility compatible

Yong Cai

caiyong@unc.edu

1 Department of Sociology and Carolina Population Center, University of North Carolina, Chapel Hill, USA 


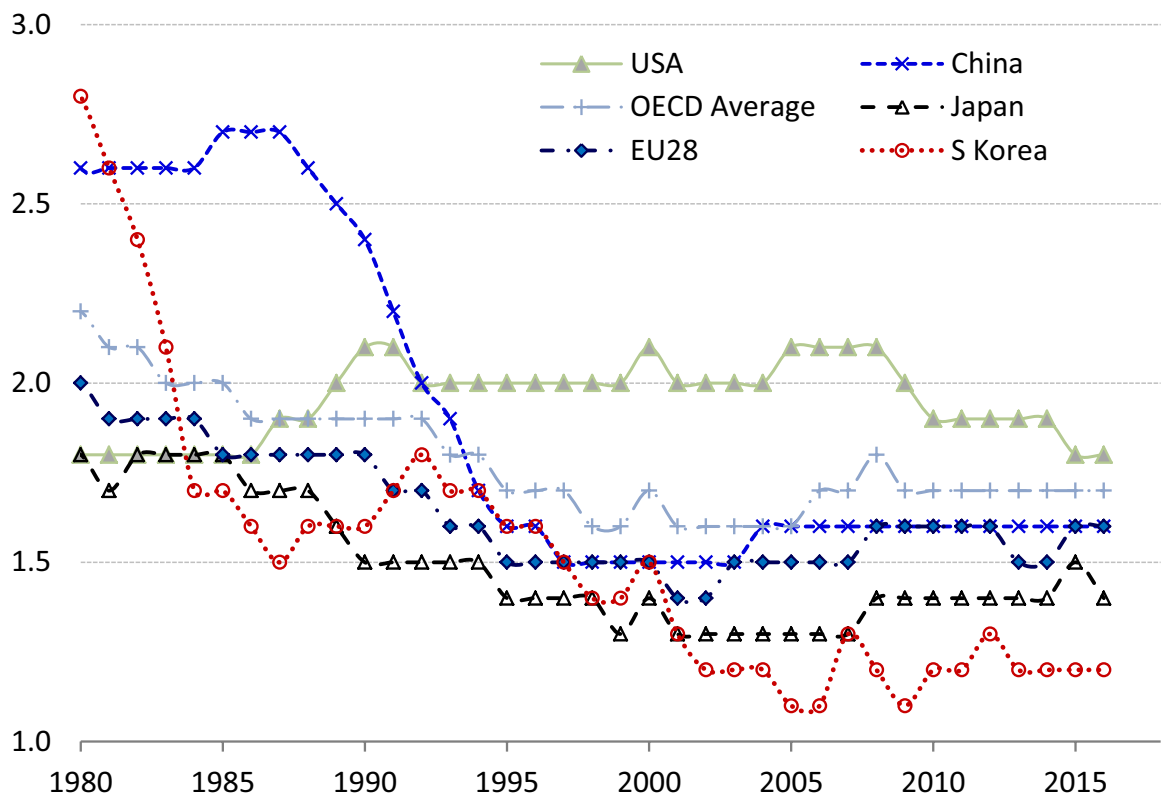

Fig. 1 Total fertility rate by year: selected countries/regions. The flat line of Chinese fertility since 2004 does not reflect the reality in China. According to annual births published by the National Bureau of Statistics of China, Chinese fertility shows an overall downward trend since 1990 with modest rebounds following the relaxation of its birth control policy in 2013 (Cai 2013; Guo et al. 2018). Source: OECD (2018), Fertility rates (indicator). https://doi.org/10.1787/8272fb01-en (Accessed on Dec 9, 2018)

with contemporary developed-country settings. Such optimism notwithstanding, for many societies, very low fertility has continued beyond a decadal time scale.

Demographers are facing a major challenge in explaining fertility trends and variations in the 21st century. The demographic transition theory (Caldwell 2007; Davis 1945; Kirk 1996; Notestein 1945), which anticipates fertility to follow mortality decline, and has worked reasonably well in Europe, in Latin America, and in Asia, seems to have lost its predictive power in the continent of Africa. Even with many conditions favorable for fertility decline, such as increases in life expectancy and female education, and with the world's concerted efforts in providing knowledge and access to contraceptives, fertility in sub-Saharan Africa remains stubbornly high (Bongaarts and Casterline 2013; Casterline 2017). At the same time, for many, but not all, countries that did complete their fertility transition, their fertility decline does not stop at the replacement level, but continues to reach a level well below replacement. Low fertility or very low fertility in many countries seems to be just as stubborn as high fertility in sub-Saharan Africa, not responding to social changes or policy efforts. What's the future of the world's fertility? Convergence? Divergence?

For more than two decades, U.S. fertility has been an interesting exception in the overall world fertility trend: U.S. fertility is "high" and "stable" for 
a developed country as shown in Fig. 1, which compares U.S., with European Union (28 countries) and the average of OECD countries. U.S. fertility has stayed close to replacement level (TFR $=2.1$ ), even with its noteworthy downward trend since the Great Recession. Figure 1 also shows a second set of cases from EastAsian, including China, Japan, and South Korea that have fertility well below replacement level, with TFRs of 1.5 or below in the most recent years. This set of low fertility countries has been at the heart of discussions about policies that might raise fertility (see McDonald 2002; Rindfuss and Choe 2015). Does the relatively high and stable U.S. fertility offers any insights for boosting fertility in the countries with low fertility? With a sizable and growing immigrant population from East Asia, what can the U.S. case tell us about lowest-low fertility in East Asia?

This paper focuses on immigrants and their descendants from China, Japan and Korea (and collectively CJK) living in the United States. As we demonstrate in the paper, CJK are growing immigrant populations in the U.S. and they are maintaining distinct fertility patterns. Specifically, the CJK populations exhibit a distinct, pervasive, and persistent pattern of late and low fertility with nearly all births occurring within marriage, compared with other groups in the United States. This is not a conventional hypothesis testing research paper, but a paper motivated by these striking empirical observations and the need for new theoretical development to account for them. Thus, the first part of our paper demonstrates the patterns of CJK fertility using straightforward description from reputable, nationally representative data sources. The second part of our paper offers a perspective on fertility difference that can account for these striking patterns. This perspective does not consistently predict that demographic differences will disappear/remain. Further, this discussion unites the literature on assimilation, segmented assimilation and pluralistic outcomes and processes. We also discuss the possible implications of these findings for countrylevel policies to increase fertility. Most generally, these discussions are a corrective to demographer's penchant for predicting secular change and convergence.

\section{Distinct, pervasive, and persistent fertility difference}

Using data from U.S. Census and American Community Survey (Ruggles et al. 2015), Table 1 shows estimates of the U.S. resident population that identifies as Chinese, Japanese or Korean. By 2010 Chinese, Japanese and Koreans together (CJK) comprise approximately $2 \%$ of the U.S. population, double the proportion 30 years earlier. Chinese are the fastest growing among these three groups. By 2010, the Chinese account for about $60 \%$ of the total CJK population. At the outset, it is important to emphasize that race/ethnicity in these data is self-identified; thus those most fully assimilating and/or in the U.S. longest may not (or no longer) identify as CJK. Likewise, and as an element of the assimilation process, high rates of intermarriage of the CJK with the broader U.S. population, may subordinate CJK identity vis-à-vis others. Thus, this self-identified measure almost certainly magnifies the differences we observe relative to measures based on the respondents' place of origin and that of their ancestors. We also stress at the outset that our use of the combined category 
Table 1 Number and percentage of U.S. residents that identify as Chinese, Japanese or Korean: By year

\begin{tabular}{|c|c|c|c|c|c|c|c|c|}
\hline \multirow[t]{2}{*}{ Race/Ethnicity } & \multicolumn{2}{|l|}{1980} & \multicolumn{2}{|l|}{1990} & \multicolumn{2}{|l|}{2000} & \multicolumn{2}{|l|}{2010} \\
\hline & Pop & $\%$ & Pop & $\%$ & Pop & $\%$ & Pop & $\%$ \\
\hline Chinese & 808,500 & 0.4 & 1637,941 & 0.6 & 2397,653 & 0.8 & 3460,421 & 1.1 \\
\hline Japanese & 725,300 & 0.3 & 846,304 & 0.3 & 778,788 & 0.3 & 783,768 & 0.3 \\
\hline Korean & 363,500 & 0.2 & 794,765 & 0.3 & 1074,871 & 0.4 & 1438,188 & 0.5 \\
\hline CJK & 1897,300 & 0.9 & 3279,010 & 1.2 & 4251,312 & 1.5 & 5682,377 & 1.9 \\
\hline
\end{tabular}

Data Sources: Integrated Public Use Microdata Series (IPUMS) USA, 1980, 1990, 2000 census micro sample (5\%) and 2010 ACS micro sample. Chinese and Japanese are identified using the condensed race variable-race, which includes all 9 major categories. Koreans are identified using the detailed version of race variable, which includes over 200 categories. All the counts do not include people identified with more than one races

CJK does not imply that these groups are similar on all dimensions; their histories including time of arrival in the U.S. vary greatly. They are combined because (as we will show) they are highly similar on the fertility characteristics that we examine and, as small populations, the cases available for analysis cannot support separate analyses. In the paper's perspectives section, we do identify common cultural features across societies that could produce the similarity we document.

The primary data source used here is the American Community Survey (ACS) of 2000-2015. As a replacement for the census long form, the ACS provides crucial and detailed information on individual characteristics, and on family formation and household composition for a very large, nationally representative U.S. sample. Regardless of marital status, all women aged 15-50, were asked whether they had given birth to any children in the past 12 months. We used responses to this question to calculate age-specific fertility rates and their summary, cumulative measure- the total fertility rate (TFR). We adjusted women's age (reduced it by.5 years) to reflect the difference between age at the time of the survey and age at the time of the recent birth. We made no effort to account for multiple births in our calculation. ${ }^{1}$ While it has been shown that the ACS over-reports fertility for women of advanced age (Cai et al. 2017), overall fertility estimates based on ACS match closely the data from national vital registration (Dye 2008, 2010; Monte and Ellis 2014).

Figure 2 shows the TFR from 2000 to 2015 for these East Asian origin groups, for the CJK group combined, for the U.S. as a whole, along with other broad race/ ethnic categories frequently examined in U.S. demographic work (i.e., non-Hispanic White, Hispanic, Black and Others). Until the Great Recession (2008 or so), the U.S. TFR was consistently near the replacement level (TFR $=2.1)$. Hispanics $(65 \%$ Mexican) have the highest estimated fertility rates and ones that have declined most across time. Both the level and the change are exaggerated by timing changes in fertility associated with time of arrival (see Parrado 2011; Parrado and Morgan 2008). The TFR for non-Hispanic Blacks has converged to that of the full population. The

\footnotetext{
1 In 2015, 3.45\% of births are multiple births (Martin et al. 2017).
} 


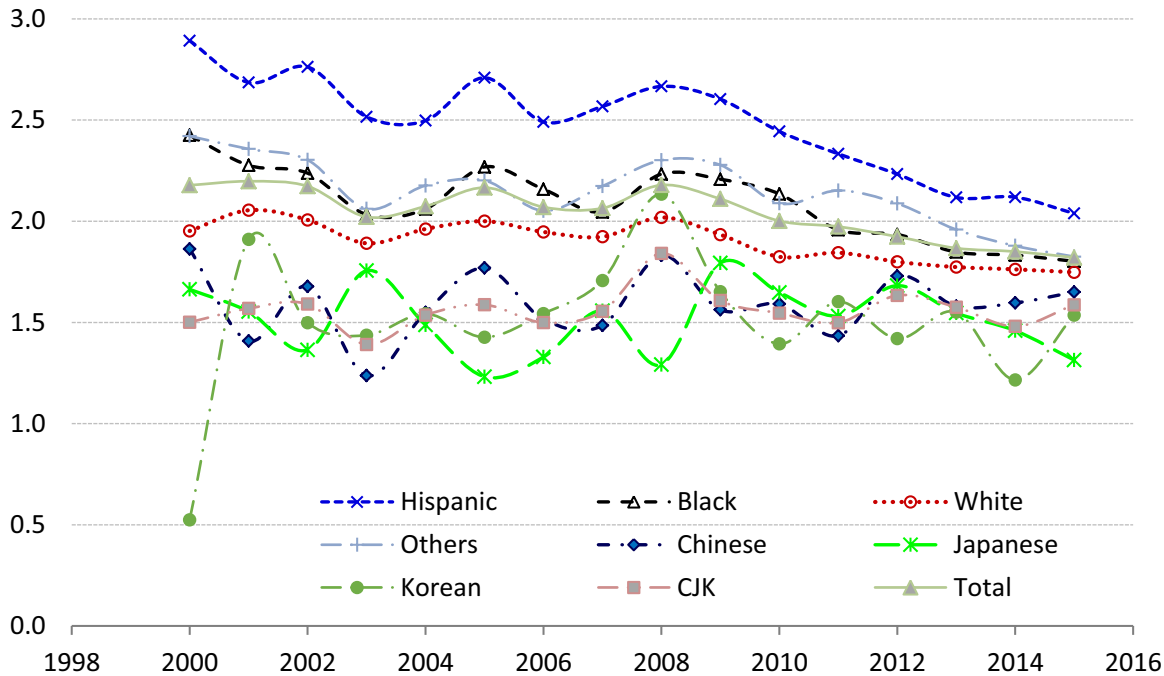

Fig. 2 Total fertility rate by race/ethnicity and year, United States 2000-15. Source: authors' calculations using American Community Survey (2010-2015)

largest U.S. race/ethnic group is the white non-Hispanic group. This group has shown modest declines beginning at the time of the Great Recession. Our focus here is on the three East Asian groups-although there is considerable year-to-year fluctuation (attributable to small sample size), these origin groups have much lower fertility, at levels of TFR around 1.5. The CJK fertility is low compared to all referents in this figure and mirrors the differences seen in origin country's fertility level (see Fig. 1).

In addition to this lower level, CJK fertility is also "postponed" compared to other groups. Figure 3 shows the age-specific fertility rates for each group (pooling the ACS data for the period 2000-15). The three East-Asian groups have a mean age at childbearing about 5 years later than the total U.S. and 4 years later than U.S. non-Hispanic whites, mirroring what has been observed in the birth registration data (Mathews and Hamilton 2016). Differences with other groups are even greater.

A third dimension on which U.S. race/ethnic groups vary greatly is the proportion of births within marriage. ${ }^{2}$ Figure 4 shows that over $90 \%$ of CJK births are marital. At the opposite extreme, non-Hispanic black's level of marital births is approximately 30\%. Non-Hispanic whites show levels that are above $70 \%$. Although there may be modest trends for some groups, especially for Hispanics and non-Hispanic

\footnotetext{
${ }^{2}$ We identify a birth as marital if the mother is reported as being married at the time of the survey (as opposed to the time of birth).
} 


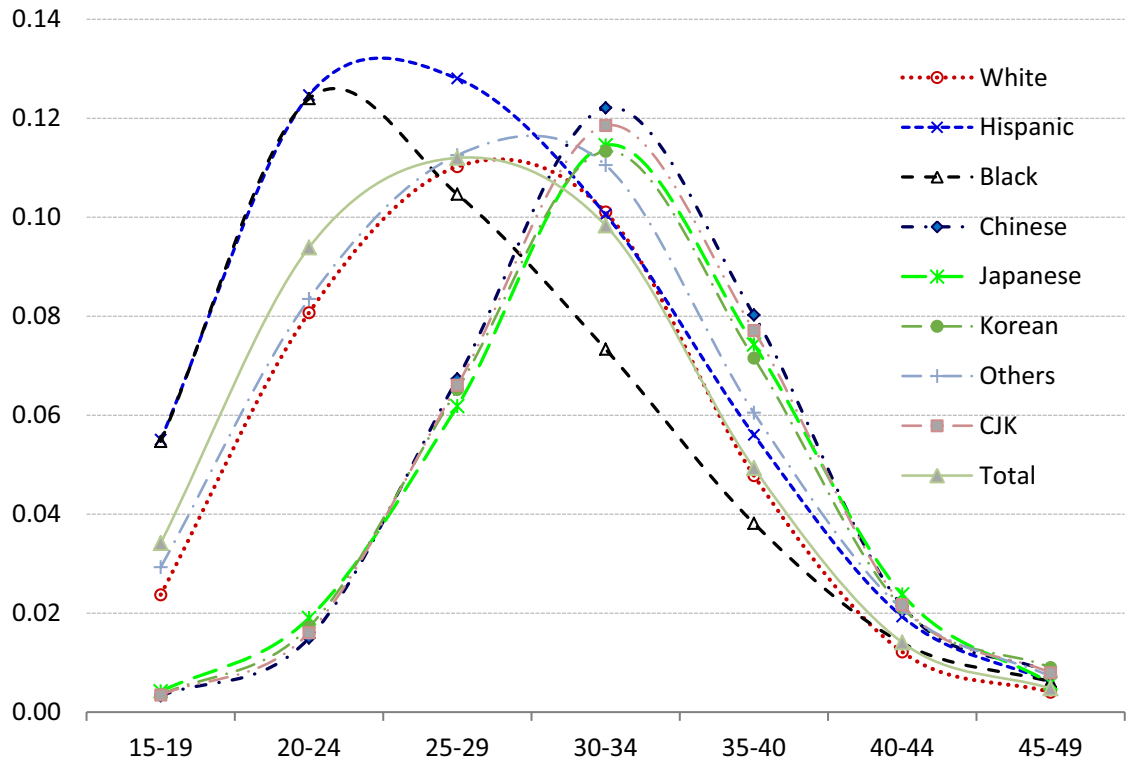

Fig. 3 Age-Specific fertility rates by age and by race/ethnicity: United States 2000-15. Source: authors' calculations using American Community Survey (2010-2015)

1.00

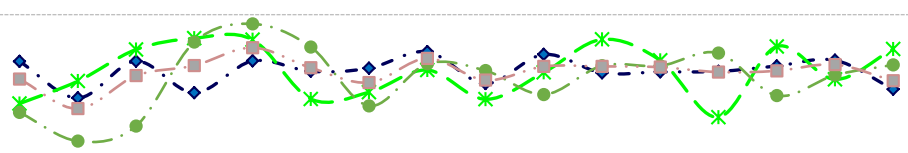

0.75

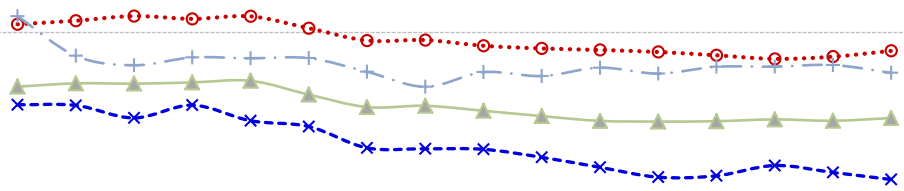

0.50

0.25

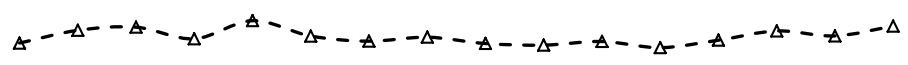

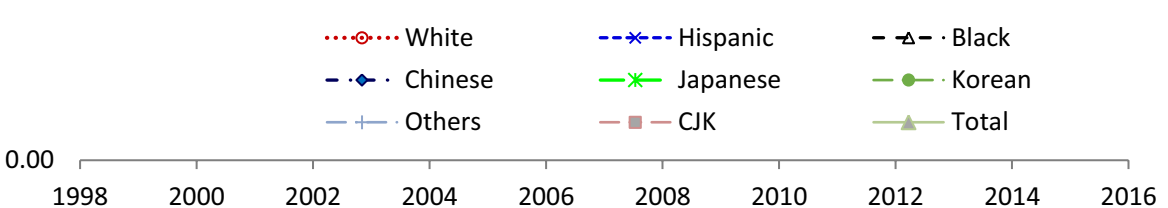

Fig. 4 Proportion of marital births by year and race/ethnicity: United States 2000-15. Source: authors' calculations using American Community Survey (2010-2015) 
Table 2 Total Fertility Rate by Race/Ethnicity, United States 2000-15. Source: authors' calculations using American community survey (2010-2015)

\begin{tabular}{lccccc}
\hline & White & Hispanic & Black & CJK & Others \\
\hline Total & 1.90 & 2.45 & 2.07 & 1.55 & 2.12 \\
US Born & & & & & \\
$\quad$ No & 2.03 & 2.85 & 2.49 & 1.63 & 2.26 \\
$\quad$ Yes & 1.89 & 2.13 & 2.00 & 1.38 & 1.87 \\
Speaking english at home & & & & \\
$\quad$ No & 2.22 & 2.59 & 2.75 & 1.61 & 2.29 \\
$\quad$ Yes & 1.88 & 2.00 & 2.01 & 1.38 & 1.87 \\
Education & & & & & \\
< High school & 2.18 & 2.99 & 2.57 & 1.85 & 2.79 \\
High school & 1.99 & 2.62 & 2.33 & 1.60 & 2.35 \\
Some college & 1.66 & 1.91 & 1.81 & 1.46 & 1.80 \\
4+college & 1.91 & 1.91 & 1.71 & 1.57 & 1.93 \\
Family income (relative to federal poverty line) & & \\
Below PL & 2.16 & 3.40 & 2.80 & 1.37 & 2.60 \\
100-299\% of PL & 2.03 & 2.37 & 1.96 & 1.72 & 2.27 \\
300-499\% of PL & 1.74 & 1.69 & 1.41 & 1.49 & 1.90 \\
500\%+ of PL & 1.51 & 1.42 & 1.17 & 1.51 & 1.59 \\
\hline
\end{tabular}

Whites, the striking feature of this figure are large, persistent differences between the CJK group and all other possible U.S. referents.

This description makes it clear that the Chinese, Japanese and Korean origin populations display distinct fertility patterns. One may suspect that these differences are short-lived and characterize only the first-generation immigrants. Table 2 shows TFR levels by race/ethnicity for various socioeconomic and demographic measures: nativity, language speaking at home, education, and poverty. Note that the foreignborn CJK have higher fertility (1.6) than their U.S. born comparison group (1.4). This difference likely reflects an effect of migration-young, childless adults are most likely to migrate. Once in the host country their fertility rates are higher for a 5-10 year period that corresponds with union formation, a pattern demonstrated for Hispanics and Mexicans and is likely broadly relevant by Parrado (2011). Note that US born women of CJK origin have TFR rates that mirror those in the origin country, below 1.5. Also shown in the table, estimates by non-English and Englishspeaking show differentials virtually indistinguishable from those in nativity due to the very strong association of English speaking and first/later generation. Neither contrast (those born in the U.S. vs not and speaking English at home vs. not) suggests that fertility is converging toward that of other groups. This persistent difference cautions against an assumption of rapid assimilation to U.S. patterns. We again 


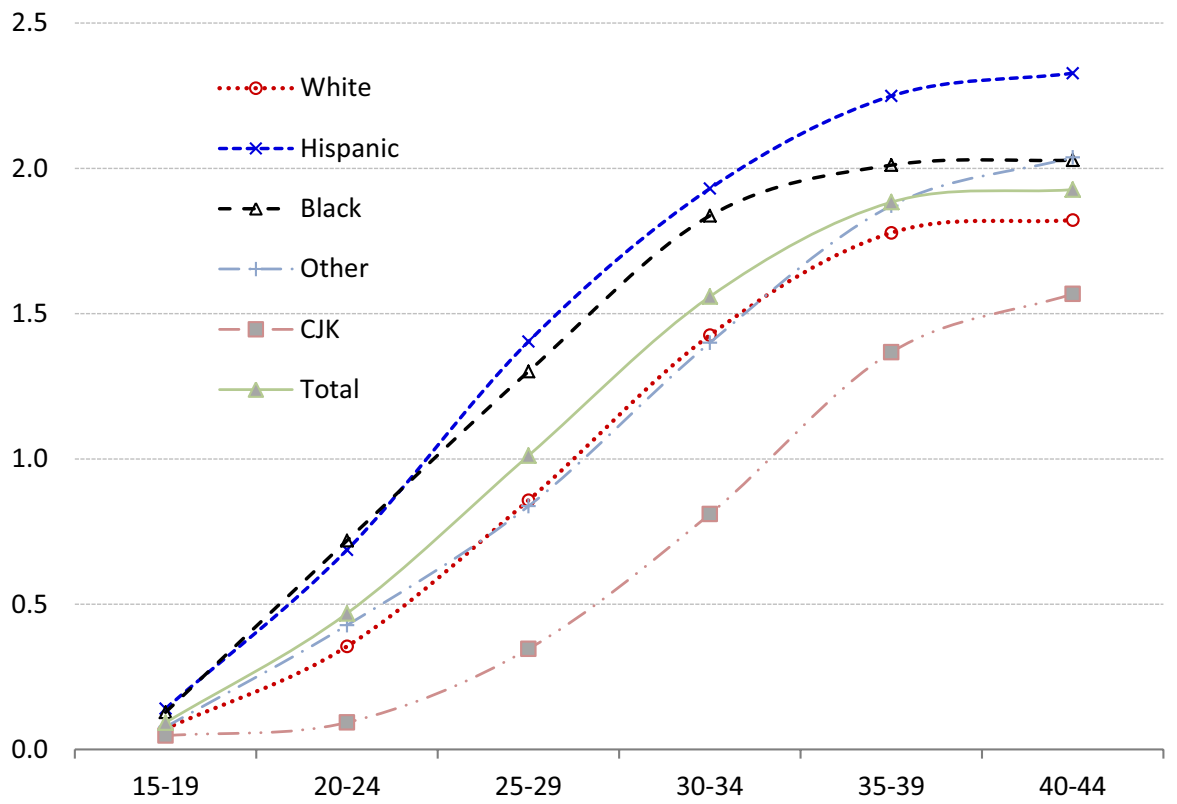

Fig. 5 Children Ever Born by Women's Age and Race/ethnicity: United States 2000-2014 Source: authors' calculations using U.S. Current Population Survey Fertility Supplement (2000-2014)

reiterate that our results may overstate stability as the individuals that have more fully assimilated (disproportionately the US born and English speaking) may no longer identify as CJK.

A second explanation for the CJK differences that we document could focus on the substantial differences across groups in social and economic status. Indeed, measures of fertility levels, timing and marital status are all influenced by the woman's educational levels and the poverty status of the household. Table 2 shows these differences for fertility levels. As expected, all groups show a fertility education gradient - those with more education have a lower TFR. We stress three other facts. First, the educational difference is smallest for the CJK group. Second, at any level of education, the CJK fertility level is lowest. And third race/ethnic differences are most consistent for the CJK groups. White/black differences, for instance, in TFR are confined to those with less than a college education. Similar patterns can be seen in fertility's relationship with household income (relative to the U.S. federal poverty line ${ }^{3}$ ). One CJK group stands out: CJK living below the poverty line have the lowest fertility - a striking contrast to other races/ethnicities where fertility is highest in the lowest income group. Thus we argue that CJK differences are pervasive across socio-economic status and that their origin is group-specific and not socio-economic.

\footnotetext{
${ }^{3}$ Federal poverty line is the U.S. federal government estimate of the thresholds below which a family of a given size has pre-tax cash income insufficient to meet minimal food and other basic needs. IPUMSACS assigns all members of each family by the family's total income for the previous year as a percentage of the poverty thresholds.
} 
Finally, some of the differences we document might be influenced by the differential geographical location of CJK groups versus others. There are well-established patterns of state and rural-urban fertility differences, and CJK populations live disproportionately in coastal areas and urban areas (where fertility is lower and later). Our data do not allow detailed controls on geographical location, but the differences we document hold if we focus on respondents located in areas with more dense concentrations of the CJK populations (for instance, in metropolitan areas. Tabulations available on request).

The distinct pattern for Chinese, Japanese and Korean origin populations shown above can be corroborated using other sources, such as the fertility supplement of the Current Population Survey (2000-2014, Flood et al. Flood et al. 2015). Figure 5 shows number of children ever born by women's age and race from CPS fertility supplements - CJK are identified by a combination of race: Asian only or Asian/ Pacific Islander, and by the respondent reporting that at least one of her parents were born in CJK). This figure provides a quasi-cohort fertility perspective. Similar to what we document using ACS data, CJK women not only start childbearing later, but earlier cohorts near the end of their reproductive years have cumulative fertility levels far below the national average.

\section{Perspectives on U.S. fertility differences}

To provide a fixed referent, non-Hispanic whites, why do the CJK have lower and later fertility and why is their fertility nearly all marital? What do we make of the differences documented above? Past work on fertility differences, by race/ethnicity, religion, and socioeconomic standing, generally assumed that the effects of these factors were transitional. As Ryder (1973) put it, as these groups became more fully integrated into American life, their behavior, including fertility-relevant behavior, would resemble that of other groups. This claim is synonymous with Goldscheider's (1971) "characteristics hypothesis" for racial/religions differences. That is, the ethnicity/race or religion association with fertility differences was spurious-depending upon associations with socioeconomic status, region of the country, rural urban residence, etc. These factors often do play a role in understanding the association of ethnicity/race with fertility at a point in time.

This view places differentials in a time-limited transitional phase; this perspective is closely linked with the literature on the assimilation of immigrant groups. Assimilation theory posits that with duration in the receiving country and across generation, immigrants and/or their decedents would become very similar, even indistinguishable, from the native population. Assimilation was assumed to operate nearly simultaneously across experience dimensions-language acquisition, socioeconomic incorporation, residential location and cultural and family behaviors. The grand scope of this theory is its greatest strength and weakness (see Hirschman 2001). Gordon's (1964) elaboration of assimilation theory acknowledged the multidimensionality of assimilation and the likelihood that assimilation on these different dimensions would operate at different paces. The idiosyncrasies of time and place 
were crucial in understanding the differential timing and pace of assimilation. But Gordon's perspective still viewed assimilation as a secular, unilinear and inevitable move toward homogeneity. Fertility and family behaviors constituted behavioral dimensions that would eventually converge with those of natives.

The segmented-assimilation perspective (see for Portes and Zhou 1993) builds on the ideas of assimilation's multidimensionality and historical/cultural idiosyncrasies to explain various patterns of integration of second generation immigrants in the post-1965 era. Portes and Zhou (1993: 96) conclude that: “...a strategy of paced, selective assimilation may prove the best course for immigrant minorities. But the extent to which this strategy is possible depends on the history of each group and its specific profile of vulnerabilities and resources." While the segmented-assimilation concept was proposed to capture the variation seen in 2 nd generation immigrant adaptation in the post-1965 U.S. context, it opens the possibility of long term difference (at least in selected domains).

Are these perspectives adequate for explaining U.S. fertility variation by race/ethnicity? The basic assimilationist perspective seems adequate to account for the transitional nature of fertility differentials for white European immigrants arriving in the U.S. at the turn of the 20th Century (see Morgan et al. 1994). On the other hand, the historical experience of non-Hispanic blacks requires a very different account-one focusing on a history of exclusion and the maintenance of family patterns adapted to this experience (see Morgan et al. 1993). But to re-focus on the evidence for East Asians above, the segmented assimilation description is an attractive explanation for the distinct behaviors of these groups. Chinese, Japanese and Koreans are sometimes referred to as "model minorities"-they achieve greater socioeconomic success than the population average (Barringer et al. 1990; Ono 2008; Zhou and Kamo 1994). This success is likely linked to the maintenance of distinctively East Asian cultural norms. Specifically, CJK women and families often reinforce traditional, family corporatist values (as opposed to individualistic ones) by investing heavily in children and stressing the importance of education as a route to success (Byun and Park 2012; Kao 1995; Schneider and Lee 1990). Further, these family values also stress the importance of "rationality" in family formation and fertility. This rationality is a mechanism that can promote family security and upward social mobility (Espenshade and Ye 1994; Greenhalgh 1988; Greenman 2011; Tang 2004). There is a large and compelling literature that links these values to fertility and family formation in the diaspora of Chinese populations that also is relevant for the Japanese and Korean populations (see Jones 2007; Lee and Wang 1999; Skinner 1997; Waters 2005; Yap 2010).

For some this will be enough "theory"; for others these descriptions do not constitute theory at all. We belong to the latter group and have additional comments for others of our kind. Specifically, we are dissatisfied with a "spice rack" of theories that we employ as needed. Demographers seem to have a strong taste for parsimony so they tend to extract only the minimum (bland) theory of what they need for the facts at hand. This makes unilinear and convergence theories attractive "spices" unless the data require a subtler taste. So, assimilation is widely applied unless the facts call for "additional theory"-in the discussion here this something else is segmented- assimilation. But both assimilation and segmented-assimilation theories are 
descriptions of outcomes and are not descriptions of processes with mechanisms identified. The literature on specific groups/times often does include discussion of specific processes/mechanisms. We need general theory that can accommodate the diversity captured in these case studies.

In our view, a theory "spice rack" should be replaced with a single theory that integrates a modest set of important concepts. Advantages of such a theory include a closer connection to key concepts shown to be valuable in prior research and an explanation that can account for a much broader range of outcomes and phenomena. In the case at hand, we need a single theory for instances where assimilation is an apt description of the outcome, and for those other cases where segmented assimilation is more accurate. Our preference is for the Theory of Conjunctural Action (TCA), a consilient theory proposed by Johnson-Hanks et al. (2011). This approach offers a theory of social structure - a very broad class of phenomena but also the type of phenomena, i.e., consistent behavioral patterns, that demographers study. Race/ethnic fertility differentials are just one example. Social structure arises and is maintained by schema held in the neural structure of individual's brains. These schemas can be shared across members of a social group, in fact group membership could be defined as sharing key schema (i.e., a common culture). Schema are "multiple" and are used selectively to motivate or rationalize behavior. This is key for thinking about the multiple dimensions of assimilation/integration. Individuals who self-identify as Chinese heritage, for instance, may infrequently choose a "Chinese" schema. In many situations or conjunctures, they would use the same schema as other groups. In the area of religious difference, Chaves (2010) identifies the expectation that "religious people" will always use "religious schema" as the religious congruence fallacy-i.e., the expectation that religious persons always invoke "religious schema". But in key situations/conjunctures, an ethnic or religious identity may encourage one to use a group-specific schema thus producing a different behavioral pattern (i.e. a distinct social structure). Because ethnicity/religion can be strongly linked to certain schema, differential ethnic behavior can persist as long as ethnicity is a relevant identity. The literature contains examples (see Goldscheider and Uhlenberg 1969; Morgan et al. 2002; Dharmalingam and Morgan 2004).

By embracing a richer set of theoretical concepts, like the TCA schema, demographers' research can advantage and be advantaged by work on other topics and in other domains. Key to CJK fertility differences (vis-à-vis non-Hispanic whites) are schemas that have historically and, we contend in the contemporary U.S., continue to motivate and rationalize a distinctive fertility structure.

\section{Implications for low fertility and policy options}

The Behavior of U.S. minority CJK groups have another logical referent-the behavior of Chinese, Japanese and Korean national populations (shown in Fig. 1). What can we learn about low fertility in the origin countries from those that trace their origin there? Or in other words, what can the East Asian diaspora tell us about lowest-low fertility in East Asia? The most common explanation for fertility differences across developed countries (like those shown in Fig. 1) are institutional 
differences (see for instance, McDonald 2000a, b). However, it is striking that East Asians who have moved to a new location-to the U.S. with its dramatically different social institutions and one of the highest fertility rates in the developed worldhave a fertility pattern that seems impervious to this dramatic contextual change. This simple observation challenges much contemporary thinking about policies to ameliorate low fertility and its negative consequences.

For example, McDonald (2006: 498) argues that all advanced countries have faced similar forces of change ("social liberalism" and "new capitalism"), and asks: "why do some have very low fertility while others have only moderately low rates?" His answer is a "cultural divide". On one side of the divide, he lists a set of countries (including the U.S.) that have "family friendly institutional arrangements" and/ or "relatively high gender equity within the family". These countries are also more advanced in terms of social liberalism (emphasis in original. See p. 500). The other group of countries that includes Japan and South Korea), "(i)ronically ... see themselves as having strong traditional family values" despite their very low fertility. These countries "share a strong tradition in which the family and state are separate entities and families are expected to support their own members without intervention from the state" (2006: 498). McDonald (2006: 500) concludes that:

The cultural divide indicates that differences between countries with very low fertility and those with moderately low fertility are due to institutional factors rather than to individual-level factors. Hence, the state, as the custodian of the country's institutions, is the logical instrument for effecting change.

In other words, McDonald (2006: 506) argues that low fertility states must intervene to produce more pronatalist institutions like those existing in countries with higher fertility. But if this is the answer, then why do the U.S., native born CJK populations have a TFR of 1.4 , a mean age of childbearing of 34 , with only $10 \%$ nonmarital births? Why do American institutions have so little influence on the East Asian diaspora's fertility regime? And if transporting East Asians to the U.S. doesn't change their fertility, why do we think transporting features of U.S./western institutions to East Asia will do the trick?

To appreciate the shortcomings of policies to "migrate institutions" requires some unpacking of the concept. What are institutions? And how do they work? Institutions produce social structure and as noted above, following Johnson-Hanks et al. (2011), this structure emerges from the interaction of virtual and material components (of institutions). This interaction occurs in conjunctures (i.e., real life situations). The virtual components are schemas, in the actors' minds and in the world (i.e., shared by others), and materials are in the world and suggest/motivate/facilitate a particular construal (and subsequent action). A third important component is identity, a constructed persona that addresses the question: how does a person like me think? How do I construe the world around me? These institutional components produce social structure. But proposals to migrate institutions face the great difficulty of moving, transplanting really, these joint components. Usually, the policy proposal is to move only material aspects of the institution, i.e., formal laws, rules and regulations that the state can mandate (see McDonald 2000a, b). In order for these materials alone to change behavior relevant schemas and identities would need to be in place. To 
adopt the ready, willing and able framework (see Lesthaeghe 2010), the assumption behind migrating institutions is that the population is "ready and willing" and only needs to be empowered by formal rules. McDonald (2000b: 12) recognizes this in his proposal to migrate gender equity:

The core change required is the one that is most difficult. Gender equity needs to be promoted within the family itself. Changes in cultural values are slow and idealized family morality is resistant to change. The direct role of government in changing family values is limited.

Most generally, the problem again is the demographer's penchant for parsimony and the secular change and convergence hypotheses that arise from very broad and simple arguments. Frequently, these broad simple arguments arise partly from the cross-sectional data we seek to understand-data that invite us to "read history sideways" (Thornton 2001, 2005). If institution " $x$ " is associated with higher fertility across countries and if we "assign" this institution to those lacking it, then we predict higher fertility. What is lost in this counterfactual is cultural and historical continuity or path dependence. The key question for raising fertility in country y is not "what raised it in country x?" Instead, what will raise fertility in country y (given its history and culture)? $?^{4}$ This is not to say that one cannot borrow lessons and practices from other countries. After all, the level of fertility in country " $x$ " is determined by its institutional arrangements. Sometimes a simple story is adequate. What worked in country x also works in country $\mathrm{y}$. But what if it does not? As argued above vis-àvis assimilation, theory is called for that can explain both cases.

\section{Conclusion}

The "data" part of this paper contrasts the fertility behavior of Chinese, Japanese and Korean (CJK) populations with other U.S. race/ethnic groups and across the immigrant and native-born distinction. A stark and persistent pattern exists- the CJK populations have fertility patterns that are "low, late and legitimate"; native born CJK populations have a TFR of 1.4, a mean age of childbearing of 34, and with only $10 \%$ nonmarital births. Limited by data availability, this research does not show more than persistence and does not suggest that fertility assimilation on dimensions studied here will not eventually take place. But on a decadal time scale, CJK fertility differences (vis-à-vis non-Hispanic whites) are clearly a durable social structure. In this regard, they resemble more closely the persistent differences between fertility behavior of white (non-Hispanic) and black Americans. The case we presented here confirms Morgan's (2015: 138-139) observation that the "U.S. case does not provide strong or clear lessons for those with much lower fertility. The fertility regime in the United States does produce replacement-level fertility, but the intermediate variables involved are not sustained by explicit policy. Rather they are sustained by historical and cultural continuity."

\footnotetext{
${ }^{4}$ For an example of this kind of thinking/policy proposal, see Tan et al. (2016).
} 
We argue that greater theoretical attention should be directed to understanding these stable demographic social structures. The "perspectives" part of our paper offers the Theory of Conjunctural Action as a framework for thinking about persistent difference. This discussion is intended as a corrective to the demographers' tendency to project and predict convergence (e.g. the World Population Prospects by UNPD). Moreover, when pressed by demographic challenges, whether it is rapid population growth or birth dearth, the first question is often what government can do or should do, i.e. policy solutions. The persistent fertility difference between CJK and other U.S. race/ethnic group, reminds us the limitation of such an approach, and calls for more careful sociological studies in people's fertility decisions using theoretical frameworks like the Theory of Conjunctural Action (TCA).

Acknowledgements This research was supported by NIH/NICHD R01-HD075560. We are grateful to the Carolina Population Center and its NIH/NICHD center grant (P2C HD050924) for general support. We thank Herbert Smith and Peter McDonald for comments on earlier drafts of this paper.

\section{References}

Barringer, H. R., Takeuchi, D. T., \& Xenos, P. (1990). Education, occupational prestige, and income of asian americans. Sociology of Education, 1, 27-43.

Bongaarts, J., \& Casterline, J. (2013). Fertility transition: is sub-saharan africa different? Population and Development Review, 38(Suppl 1), 153-168.

Byun, S.-Y., \& Park, H. (2012). The academic success of East Asian American youth: the role of shadow education. Sociology of Education, 85(1), 40-60.

Cai, Y. (2013). China's new demographic reality-learning from the 2010 census. Population and Development Review, 39, 371-396.

Cai, Y., Rybińska, A. (2017).'Missing babies' and 'missing mothers' in the American community survey: data problems and social differentiations. Presented at the population association of America 2018 Annual Meeting, Denver, Colorado

Caldwell, J. C. (2007). Demographic transition theory. Dordrecht: Springer Science \& Business Media.

Casterline, J. B. (2017). Prospects for fertility decline in Africa. Population and Development Review, 43(S1), 3-18.

Chaves, M. (2010). SSSR presidential address rain dances in the dry season: overcoming the religious congruence fallacy. Journal for the Scientific Study of Religion, 49(1), 1-14.

Davis, K. (1945). The world demographic transition. The Annals of the American Academy of Political and Social Science, 237(1), 1-11.

Dharmalingam, A., \& Morgan, S. P. (2004). Pervasive muslim-hindu fertility differences in India. Demography, 41(3), 529-545.

Dye, J. L. (2008). Fertility of American Women: 2006. Washington, DC.: Census Bureau. Retrieved October 2, 2015 (https://www.census.gov/prod/2008pubs/p20-558.pdf). Accessed 2 Oct 2015.

Dye, J. L. (2010). Fertility of American women: 2008. Washington: U.S. Census Bureau.

Espenshade, T. J., \& Ye, W. (1994). Differential fertility within an ethnic minority: the effect of 'trying harder' among Chinese-American women. Social Problems, 41(1), 97-113.

Flood, S., King, M., Ruggles, S., Warren, R. (2015) Integrated Public Use Microdata Series, Current Population Survey: Version 4.0. [dataset]. Minneapolis: University of Minnesota. http://doi. org/10.18128/D030.V4.0.

Goldscheider, C. (1971). Population, modernization, and social structure. Boston: Little, Brown and Company.

Goldscheider, C., \& Uhlenberg, P. R. (1969). Minority group status and fertility. American Journal of Sociology, 74(4), 361-372. 
Greenhalgh, S. (1988). Fertility as mobility: sinic transitions. Population and Development Review, 14(4), 629-674.

Greenman, E. (2011). Asian American-white differences in the effect of motherhood on career outcomes. Work and Occupations, 38(1), 37-67.

Guo, Z., Gietel-Basten, S., \& Gu, B. (2018). The lowest fertility rates in the world? Evidence from the 2015 Chinese 1\% sample census. China Population and Development Studies, 2018, 1-4. https:// doi.org/10.1007/s42379-018-0012-1.

Hirschman, C. (2001). The educational enrollment of immigrant youth: a test of the segmented-assimilation hypothesis. Demography, 38(3), 317-336.

Johnson-Hanks, J. A., Bachrach, C. A., \& Morgan, S. P. (2011). Understanding family change and variation: toward a theory of conjunctural action (2011th ed.). Dordrecht: Springer.

Jones, G. W. (2007). Delayed Marriage and very low fertility in Pacific Asia. Population and Development Review, 33(3), 453-478.

Kao, G. (1995). Asian Americans as model minorities? A look at their academic performance. American Journal of Education, 103(2), 121-159. https://doi.org/10.1086/444094.

Kirk, D. (1996). Demographic transition theory. Population Studies, 50(3), 361-387.

Lee, J. Z., \& Wang, F. (1999). One quarter of humanity: malthusian mythology and Chinese realities, 1700-2000. Cambridge: Mass. Harvard University Press.

Lesthaeghe, R. (2010). The unfolding story of the second demographic transition. Population and Development Review, 36(2), 211-251.

Martin, J. A., Hamilton, B. E., Osterman, M. J., Driscoll, A. K., \& Mathews, T. J. (2017). Births: final data for 2015. National Vital Statistics Reports Centers for Disease Control and Prevention, National Center for Health Statistics, National Vital Statistics System, 66(1), 1.

Mathews, T. J., \& Hamilton, B. E. (2016). Mean age of mothers is on the rise: United States, 2000-2014. NCHS Data Brief, no. 232, 1-8.

McDonald, P. (2000a). Gender equity in theories of fertility transition. Population and Development Review, 26(3), 427-439.

McDonald, P. (2000b). Gender equity, social institutions and the future of fertility. Journal of the Australian Population Association, 17(1), 1-16.

McDonald, P. (2002). Sustaining fertility through public policy: the range of options. Population, 57(3), $417-446$.

McDonald, P. (2006). Low fertility and the state: the efficacy of policy. Population and Development Review, 32(3), 485-510. https://doi.org/10.1111/j.1728-4457.2006.00134.x.

Gordon, M. M. (1964). Assimilation in American life: the role of race, religion, and national origins. New York: Oxford University Press.

Monte, L. M., \& Ellis, R. R. (2014). Fertility of women in the United States: 2012. Current population reports, P20-575. Washington: US Census Bureau.

Morgan, S. P. (2003). Is low fertility a twenty-first-century demographic crisis? Demography, 40(4), 589-603.

Morgan, S. P. (2015). Variation in U.S. Fertility: low and not so low, but not lowest-low. In M. K. Choe (Ed.), Rindfuss RR. Low and Lower Fertility (pp. 125-141). Berlin: Springer International Publishing.

Morgan, S. P., McDaniel, A., Miller, A. T., \& Preston, S. H. (1993). Racial differences in household and family structure at the turn of the century. American Journal of Sociology, 98(4), 799-828.

Morgan, S. P., Stash, S., Smith, H. L., \& Mason, K. O. (2002). Muslim and non-muslim differences in female autonomy and fertility: evidence from four Asian countries. Population and Development Review, 28(3), 515-537.

Morgan, S. P., Watkins, S. C., \& Ewbank, D. (1994). Generating Americans: the fertility of the foreignborn in the U.S. In S. C. Watkins (Ed.), After Ellis island: a 1910 census monograph (pp. 19051910). New York: Russell Sage Foundation.

Notestein, F. W. (1945). Population: the long view. In T. W. Schultz (Ed.), Food for the world (pp. 36-57). Chicago: University of Chicago Press.

Ono, K. A. (2008). A companion to Asian American studies. Hoboken: Wiley.

Parrado, E. A. (2011). How high is hispanic/mexican fertility in the United States? Immigration and tempo considerations. Demography, 48(3), 1059-1080.

Parrado, E. A., \& Philip Morgan, S. (2008). Intergenerational fertility among hispanic women: new evidence of immigrant assimilation. Demography, 45(3), 651-671. 
Portes, A., \& Zhou, M. (1993). The new second generation: segmented assimilation and its variants. The Annals of the American Academy of Political and Social Science, 530(1), 74-96.

Rindfuss, R.R., Choe, M.K. (2015) Diversity across Low-Fertility Countries: An Overview. In: R. R. Rindfuss and M. K. Choe (Ed.), Low and Lower Fertility: Variations across Developed Countries, Springer International Publishing (pp. 1-13), Retrieved February 22, 2017 (http://link.springer.com/ chapter/10.1007/978-3-319-21482-5_1).

Ruggles, S., Genadek, K., Goeken, R., Grover, J., Sobek, M. (2015). Integrated Public Use Microdata Series: Version 6.0 [dataset]. Minneapolis: University of Minnesota, http://doi.org/10.18128/D010. V6.0.

Ryder, N. B. (1973). Recent Trends and Group Differences in Fertility. In C. F. Westoff (Ed.), Toward the End of Growth: Population in America, (pp. 57-68). Englewood Cliffs: Prentice-Hall.

Schneider, B., \& Lee, Y. (1990). A model for academic success: the school and home environment of east asian students. Anthropology \& Education Quarterly, 21(4), 358-377.

Skinner, G. W. (1997). Family systems and demographic processes. In D. I. Kertzer, T. Fricke (Eds.), Anthropological demography: toward a new synthesis (pp. 53-95). Chicago: University of Chicago Press.

Tan, P. L., Morgan, S. P., \& Zagheni, E. (2016). A case for 'reverse one-child' policies in japan and south Korea? Examining the link between education costs and lowest-low fertility. Population Research and Policy Review, 35(3), 327-350.

Tang, Z. (2004). Immigration and Chinese reproductive behavior in Canada. Social Biology, 51(1-2), 37-53.

Thornton, A. (2001). The developmental paradigm, reading history sideways, and family change. Demography, 38(4), 449-465.

Thornton, A. (2005). Reading history sideways: the fallacy and enduring impact of the developmental paradigm on family life. Chicago: University of Chicago Press.

Waters, J. L. (2005). Transnational family strategies and education in the contemporary Chinese Diaspora. Global Networks, 5(4), 359-377.

Yap, K. B. (2010). The impact of host country policies on the overseas Chinese family in Singapore. Journal of Macromarketing, 30(4), 354-365.

Zhou, M., \& Kamo, Y. (1994). An analysis of earnings patterns for Chinese, Japanese, and non-hispanic white males in the United States. The Sociological Quarterly, 35(4), 581-602.

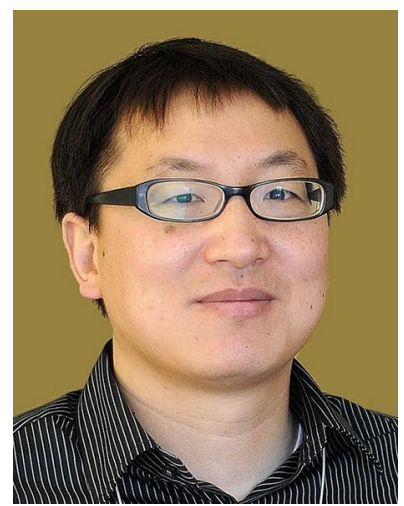

Yong Cai studies social change and social inequality from a demographic perspective, with a strong empirical focus on China. His work on China's low fertility demonstrates that a major part of fertility decline in China happened before the one-child policy, and current low fertility in China has more to do with structural changes brought by socioeconomic development as well as cultural features deeply embedded in Chinese society. His uses the National Transfer Accounts method to examine the social and fiscal pressure associated with China's rapid aging. 


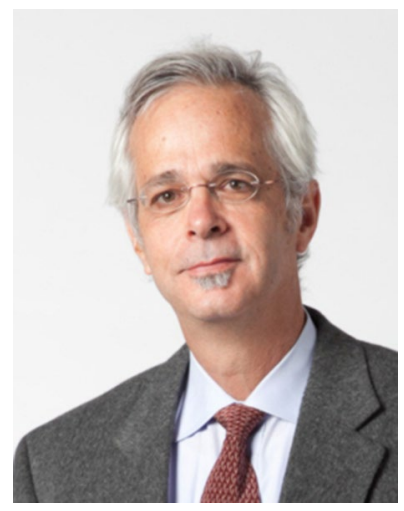

Phil Morgan's research focuses on change and variation in the human family, with special attention to human fertility. His work on fertility in the United States examines fertility levels (that hover near the replacement level of approximately two births per woman), fertility timing (which is highly variable with teen childbearing and delayed childbearing common), and high levels of nonmarital childbearing. Morgan also studies cross-national variation in low fertility among developed countries and the differential pace of fertility decline in developing ones. 